\title{
Revisiting the association of blood pressure with mortality in oldest old people in China: community based, longitudinal prospective study
}

\author{
Yue-Bin Lv, ${ }^{1}$ Xiang Gao, ${ }^{2}$ Zhao-Xue Yin, ${ }^{3}$ Hua-Shuai Chen, ${ }^{4}$ Jie-Si Luo, ${ }^{3}$ Melanie Sereny Brasher, ${ }^{5}$ \\ Virginia Byers Kraus, ${ }^{6}$ Tian-Tian Li, ${ }^{1}$ Yi Zeng, ${ }^{47}$ Xiao-Ming Shi ${ }^{1}$
}

${ }^{1}$ National Institute of

Environmental Health, Chinese

Center for Disease Control and

Prevention, Beijing, China

${ }^{2}$ Nutritional Epidemiology Lab,

Pennsylvania State University,

Philadelphia, PA, USA

${ }^{3}$ Division of Non-Communicable Disease Control and Community

Health, Chinese Center for

Disease Control and Prevention,

Beijing, China

${ }^{4}$ Center for the study of Aging and Human Development and

the Geriatric Division of School

of Medicine, Duke University,

Durham, NC, USA

${ }^{5}$ Department of Sociology and Anthropology and Department of Human Development and

Family Studies, University of

Rhode Island, Kingston, RI, USA

${ }^{6}$ Duke Molecular Physiology

Institute and Division of

Rheumatology, Department of

Medicine, Duke University School

of Medicine, Durham, NC, USA

${ }^{7}$ Center for Study of Healthy

Aging and Development

Studies, Peking University,

Beijing, China

Correspondence to: X-M Shi

shixm@chinacdc.cn

Additional material is published online only. To view please visit

the journal online.

Cite this as: $B M / 2018 ; 361: k 2158$ http://dx.doi.org/10.1136/bmj.k2158

Accepted: 17 April 2018

\section{ABSTRACT}

OBJECTIVE

To examine the associations of blood pressure with all cause mortality and cause specific mortality at three years among oldest old people in China.

DESIGN

Community based, longitudinal prospective study.

SETTING

2011 and 2014 waves of the Chinese Longitudinal Healthy Longevity Survey, conducted in 22 Chinese provinces.

\section{PARTICIPANTS}

4658 oldest old individuals (mean age 92.1 years).

\section{MAIN OUTCOME MEASURES}

All cause mortality and cause specific mortality assessed at three year follow-up.

RESULTS

1997 deaths were recorded at three year follow-up. U shaped associations of mortality with systolic blood pressure, mean arterial pressure, and pulse pressure were identified; values of $143.5 \mathrm{~mm} \mathrm{Hg}, 101 \mathrm{~mm} \mathrm{Hg}$, and $66 \mathrm{~mm} \mathrm{Hg}$ conferred the minimum mortality risk, respectively. After adjustment for covariates, the $U$ shaped association remained only for systolic blood pressure (minimum mortality risk at $129 \mathrm{~mm} \mathrm{Hg}$ ). Compared with a systolic blood pressure value of 129 $\mathrm{mm} \mathrm{Hg}$, risk of all cause mortality decreased for values lower than $107 \mathrm{~mm} \mathrm{Hg}$ (from 1.47 (95\% confidence interval 1.01 to 2.17 ) to 1.08 (1.01 to 1.17 )), and increased for values greater than $154 \mathrm{~mm} \mathrm{Hg}$ (from 1.08 (1.01 to 1.17$)$ to 1.27 (1.02 to 1.58$)$ ). In the

\section{WHAT IS ALREADY KNOWN ON THIS TOPIC}

Hypertension and hypotension are well established risk factors of morbidity and survival in middle aged or younger elderly people, while the association weakens with age

For people aged 80 years and older, previous studies regarding the role of blood pressure in all cause mortality and cause specific mortality have generated conflicting results

\section{WHAT THIS STUDY ADDS}

Among a study sample group of oldest old people in China, systolic blood pressure showed a $U$ shaped association with three year all cause mortality Higher values of systolic blood pressure predicted a higher risk of cardiovascular mortality, and lower values predicted a higher risk of non-cardiovascular mortality

The present paradigm of "the lower the better" in blood pressure regulation does not apply to oldest old people, and optimal blood pressure might need revisiting after age 80 years

cause specific analysis, compared with a middle range of systolic blood pressure (107-154 mm Hg), higher values (>154 $\mathrm{mm} \mathrm{Hg}$ ) were associated with a higher risk of cardiovascular mortality (adjusted hazard ratio 1.51 (95\% confidence interval 1.12 to 2.02$)$ ); lower values $(<107 \mathrm{~mm} \mathrm{Hg})$ were associated with a higher risk of non-cardiovascular mortality (1.58 (1.26 to 1.98)). The $U$ shaped associations remained in sensitivity and subgroup analyses.

\section{CONCLUSIONS}

This study indicates a $U$ shaped association between systolic blood pressure and all cause mortality at three years among oldest old people in China. This association could be explained by the finding that higher systolic blood pressure predicted a higher risk of death from cardiovascular disease, and that lower systolic blood pressure predicted a higher risk of death from non-cardiovascular causes. These results emphasise the importance of revisiting blood pressure management or establishing specific guidelines for management among oldest old individuals.

\section{Introduction}

Hypertension and hypotension are well established risk factors of morbidity and survival before the age of 80 years $^{12}$; however, the contribution of those conditions to all cause mortality weakens with ageing. Whether this attenuation is a natural ageing process or a pathological process that should to be intervened remains unclear. The number of oldest old people (aged $\geq 80$ years) will be the fastest growing group between now and 2050; therefore, it is important to determine whether a significant association exists between blood pressure and all cause mortality or cause specific mortality in this age group. However, conflicting results have been reported-especially regarding systolic blood pressure and diastolic blood pressure. Most observational studies have found that changes in systolic or diastolic blood pressure predicted higher mortality risk, ${ }^{3-11}$ even showing a J or U shaped association ${ }^{12-14}$; however, some have failed to detect significant association between blood pressure and mortality. ${ }^{1516}$ One meta-analysis showed that higher systolic blood pressure predicted increased mortality risk in all age groups, including oldest old people. ${ }^{17}$ Furthermore, some experimental studies have found that the treatment of isolated systolic hypertension prevented stroke and heart failure; but findings regarding prevention against all cause mortality have been conflicting for people aged over 80 years. $^{18-21}$ 
The following limitations with previous studies need to be addressed: $:^{3-21}$

- The number of oldest old participants was limited $(<1000)$ in most studies. Most participants were octogenarians and nonagenarians, with centenarians under-represented.

- Most studies focused on specific populations or high risk populations (eg, patients with hypertension); studies on community based populations were lacking.

- No linear or curvilinear associations were examined by Cox models with penalised splines, ${ }^{22}$ which is a valid approach for determining the shapes of the association.

- No previous studies focused on the role of mean arterial pressure; very few studies investigated pulse pressure, ${ }^{7}$ which may be more salient blood pressure indexes for mortality in this age group. ${ }^{2324}$

- Most studies were implemented in developed countries (Finland, Japan, Netherlands, Spain, Sweden, United States), while research in developing countries is very limited regarding the potential role of blood pressure in mortality among this age group. In the present community based study, we aimed to deal with some of these existing gaps, by examining the role of blood pressure in all cause mortality or cause specific mortality among 4658 oldest old people during a three year follow-up. We used Cox models with penalised splines in our primary analyses and accounted for several important confounding factors, including clinical diseases, frailty, and functional impairment.

\section{Methods}

\section{Study cohort}

Participants were recruited from the sixth wave (2011) Chinese Longitudinal Healthy Longevity Survey (CLHLS). A multistage cluster sampling approach was used in this prospective, longitudinal, community based study. We initially selected 22 provinces of China (Beijing, Tianjin, Chongqing, Shanghai, Anhui, Fujian, Guangdong, Guangxi, Hubei, Hunan, Henan, Hebei, Heilongjiang, Liaoning, Jiangxi, Jiangsu, Jilin, Shandong, Shaanxi, Shanxi, Sichuan, and Zhejiang); we then randomly selected half the cities or counties in these provinces.

All centenarians were interviewed in the 801 randomly selected cities or counties. Nearby individuals (eg, in the selected street or village, or in the selected city or county) were invited to be investigated to match with each centenarian. These matched individuals included younger elderly people (aged 65-79 years), octogenarians, and nonagenarians of predefined sex and age. The predefined sex and age were in accordance with the centenarians' randomly assigned code numbers. This process ensured that the numbers of randomly selected men and women were comparable in the three age groups (65-79, 80-89, 9099 years). A more detailed description of the CLHLS has been published elsewhere. ${ }^{25}$ Based on systematic assessments of the randomness of attrition, credibility and validity of the measurement scale, and accuracy of reported age, the quality of the data for this study was high. ${ }^{25} 26$

In all, 7328 elderly individuals were initially included in the 2011 CLHLS. We excluded 2670 participants because they were younger elderly $(\leq 79$ years; $n=2437)$, had incorrect death dates $(n=43)$, or were lacking blood pressure values $(n=190)$. Finally, 4658 oldest old participants met the inclusion criteria (2001 octogenarians, 1832 nonagenarians, and 825 centenarians; fig S1). A structured questionnaire was used by a trained staff member from the county Centers for Disease Control and Prevention to conduct interviews. The information was collected from proxy respondents, usually close family member or spouse, if participants were unable to answer questions.

During the three year study period, 247 (5.3\%) participants were lost to follow-up (fig S1). The participants' survival status and date of death were collected during the follow-up survey in 2014. Information about death was ascertained and affirmed by the close family member or village doctor of the participant. Participants who could not be found or contacted were designated as lost to follow-up. ${ }^{27} \mathrm{~A}$ supplementary phone interview was conducted to obtain information about antihypertensive treatment in participants who self reported hypertension and about cause specific mortality (cardiovascular $V$ non-cardiovascular) mortality in decedents. We used ICD-10 (international classification of diseases, 10th revision) to assess participants' underlying cause of death from cardiovascular disease (codes I00-I78) or ischaemic heart disease (I20-I25). In all, 339 $(28.4 \%)$ of 1195 patients with hypertension were successfully followed up; details of cause of death for $1088(54.5 \%)$ participants were successfully obtained. A statistical analysis of cardiovascular and non-cardiovascular mortality is in the online supplemental material.

\section{Measurement and calculation of blood pressure}

After participants had rested for at least five minutes, research assistants took two measurements of blood pressure on the right arm by mercury sphygmomanometer (upper arm type; Yuyue, Jiangsu, China). Korotkoff phase I was designated for the systolic blood pressure values, phase $\mathrm{V}$ for the diastolic blood pressure values. For bedbound participants, blood pressure measurements were obtained in a recumbent position. For further analyses, the mean value was calculated with the two measurements (pulse pressure=systolic blood pressure-diastolic blood pressure; mean arterial pressure $=$ (systolic blood pressure $+(2 \times$ diastolic blood pressure $)) \div 3$.

\section{Assessment of covariates}

Covariates were obtained by use of a structured questionnaire. One section included sociodemographic characteristics, comprising details of age, sex, educational background, residence, marital status, and economic income. The other section dealt with 
health characteristics; it covered smoking, drinking, activities of daily living, visual function, cognition, body mass index, waist circumference, and self reported diseases diagnosed by a doctor-for instance, diabetes mellitus, stroke and other cerebrovascular diseases, cardiovascular disease, respiratory disease, and cancer.

Residence was categorised as urban (city residence) or rural (town or countryside residence). Marital status was categorised as "not in marriage" if a participant had never married or was widowed or divorced and "in marriage" if a participant was currently married. Economic income was classified as "high" and "medium or low" by the question "Compared with other locals, how do you think about your economic position?" Current smoking practice and alcohol consumption habits were assessed by self report based on the questions "Do you currently smoke?" and "Do you currently drink alcohol?”

Visual function was classified as "good" or "poor" according to whether participants were able to identify the break in the image of a circle held before them. A non-stretchable tape was used to measure waist circumference with the participant lightly clothed; measurement was made between the iliac crest and the lowest rib. Central obesity was defined as a waist circumference at least $80 \mathrm{~cm}$ for women and at least $85 \mathrm{~cm}$ for men. Body mass index was calculated as bodyweight $(\mathrm{kg})$ divided by squared body height $\left(\mathrm{m}^{2}\right)$. We defined cognitive impairment as a mini-mental status examination score lower than 24. Restriction in activities of daily living was defined as a participant being dependent in toileting, bathing, indoor activities, dressing, eating, or continence. We defined comorbidity as 0 or at least 1 according to the number of diseases (stroke and other cerebrovascular diseases, cardiovascular disease, diabetes mellitus, respiratory disease, and cancer) that the participant had.

Frailty was defined by the study of osteoporotic fractures index. ${ }^{28}$ The index included three components: underweight (body mass index<18.5); participants having trouble standing up from a chair without the assistance of arms; and a positive response to the question "Over the last 6 months, have you been limited in activities because of a health problem?," indicating reduced energy level. We categorised frailty in three states: frail (two or three components); prefrail (one component); and robust (no components), which showed good ability for biological age among Chinese elderly people. ${ }^{29}$ Overall, few data for the covariates were missing $(<3 \%)$ : fewer than $1 \%$ of the data were missing for any single variable, and we did multiple imputation methods for the correction of missing data in covariates. ${ }^{30} 31$

\section{Statistical analysis}

We used the Kaplan-Meier method to calculate all cause mortality. We determined the survival time for decedents as the period between the baseline survey and death; censoring was performed at three years for surviving participants or those lost to follow-up. We compared the characteristics between surviving and deceased participants and between those lost to follow-up and those successfully followed up, using univariate Cox models for continuous variables and the log rank test for categorical variables.

To examine the non-linear or irregular shape of the hazard functions, we used Cox models with penalised splines using non-parametric smoothers. We calculated the hazard function for the i-th participant in the $\mathrm{j}$-th group $\mathrm{as}^{32}$ :

$$
\lambda_{\mathrm{j}, \mathrm{i}}(\mathrm{t})=\lambda_{\mathrm{j}, 0}(\mathrm{t}) \exp \left(\mathrm{Z}_{\mathrm{i}}(\mathrm{t}) \beta_{\mathrm{z}}+\mathrm{s}\left(\mathrm{X}_{\mathrm{i}}(\mathrm{t}), \mathrm{df}_{\mathrm{i}}\right)\right)
$$

Where $\lambda_{\mathrm{j}, 0}=$ unspecified underlying hazard function; $\beta_{\mathrm{z}}=$ vector of parameters for covariate $\mathrm{Z}_{\mathrm{i}}(\mathrm{t})$, and $\mathrm{s}\left(\mathrm{X}_{\mathrm{i}}(\mathrm{t}), \mathrm{df}_{\mathrm{i}}\right)=$ penalised splines of covariates with the corresponding degree of freedom (df).

With this model, we used the penalised partial likelihood to estimate the parameters; we selected penalised splines as smoothers (or spline functions). ${ }^{32-34}$ We performed Cox models with penalised splines twice. To determine whether linear terms or flexible spline terms should be used in further analyses, we examined the association of a continuous variable (eg, blood pressure, age, educational background, and body mass index) with mortality in the univariate Cox models with penalised splines. If the association between a continuous variable and mortality was linear, we used linear terms for that variable in further analyses using multivariate Cox models with penalised splines. If the association between a continuous variable and mortality was nonlinear, we used flexible spline terms for that variable in further analyses using multivariate Cox models with penalised splines.

We found the association of age (years), time spent in education (years), and body mass index with mortality to be linear (fig S2), while the associations of systolic blood pressure, diastolic blood pressure, mean arterial pressure, and pulse pressure with mortality were nonlinear (fig S3). Therefore, we used linear terms for age, educational background, and body mass index; we used flexible spline terms for systolic blood pressure, diastolic blood pressure, mean arterial pressure, and pulse pressure when performing multivariate Cox models with penalised splines. Based on the corrected Akaike information criterion, we selected the degree of freedom as 3 for systolic blood pressure, diastolic blood pressure, mean arterial pressure, and pulse pressure; this method had been considered as the most reliable, flexible criterion for fitting penalised splines in Cox models. ${ }^{35}$ In final Cox models with penalised splines, we made adjustments for: sex, age (as a linear term), marital status, educational background (as a linear term), residence, economic income, current smoking, current alcohol consumption, cognitive impairment, restriction on activities of daily living, poor visual function body mass index (as a linear term), central obesity, diabetes mellitus, cardiovascular disease, stroke and other cerebrovascular diseases, respiratory disease, cancer, and frailty. 


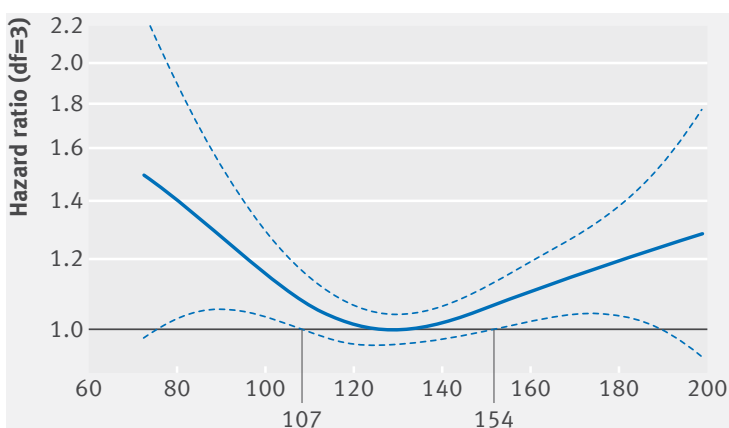

Systolic blood pressure (non-linear; $\mathrm{P}=0.04$ )

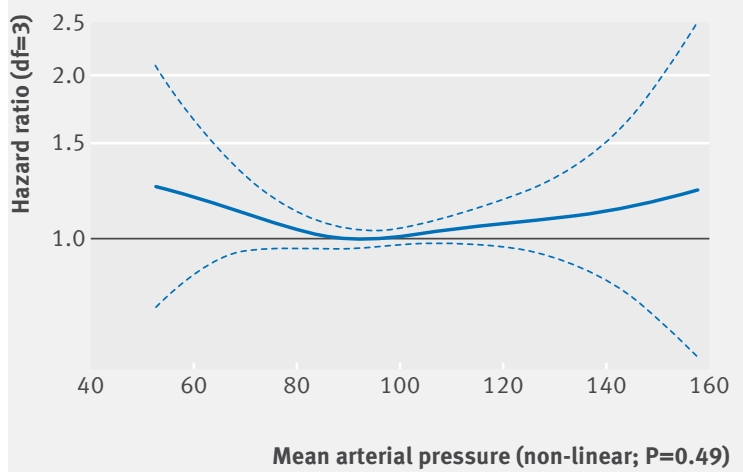

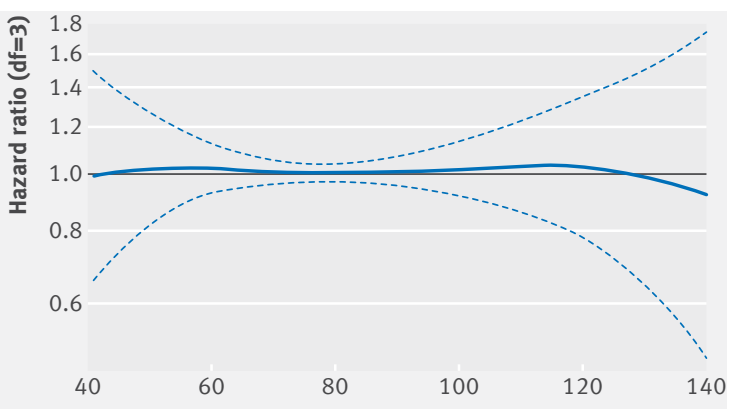

Diastolic blood pressure (non-linear; $\mathrm{P}=\mathbf{0 . 7 8}$ )

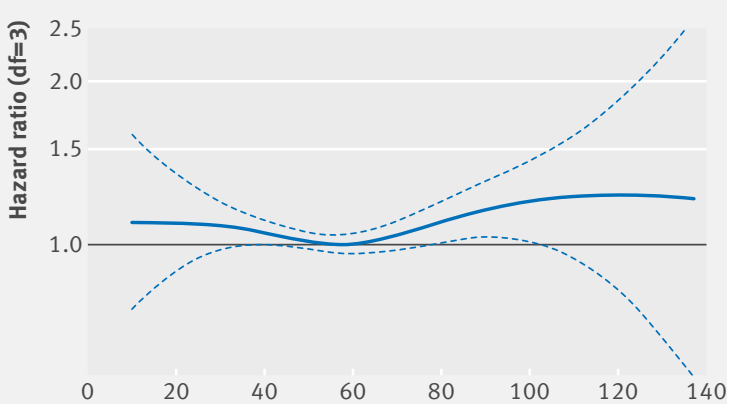

Pulse pressure (non-linear; $\mathrm{P}=\mathbf{0 . 1 4}$ )

Fig 1 | Associations of blood pressure with three year all cause mortality in study population of Chinese oldest old people, in Cox models with penalised splines after adjustment. Lines=estimated hazard ratio of systolic blood pressure (129 $\mathrm{mm} \mathrm{Hg}$ reference), diastolic blood pressure $(80 \mathrm{~mm} \mathrm{Hg})$, mean arterial pressure $(90 \mathrm{~mm} \mathrm{Hg})$, and pulse pressure $(57.5 \mathrm{~mm} \mathrm{Hg})$ for risk of three year all cause mortality; dotted lines=95\% confidence intervals; $\mathrm{df}=\mathrm{deg}$ rees of freedom

Cox models with penalised splines showed a statistically significant U shaped association for systolic blood pressure with three year all cause mortality. Participants with $129 \mathrm{~mm} \mathrm{Hg}$ systolic blood pressure had the minimum mortality risk based on the estimated parameters of penalised splines after adjustment (fig 1, fig 2). Compared with individuals having $129 \mathrm{~mm} \mathrm{Hg}$ systolic blood pressure, the risk of all cause mortality at three years was significantly higher in participants with systolic blood pressure lower than $107 \mathrm{~mm} \mathrm{Hg}$ or higher than $154 \mathrm{~mm} \mathrm{Hg}(\mathrm{P}<0.05$; fig 1, fig 2). The Cox models with penalised splines showed $U$ shaped associations for diastolic blood pressure, mean arterial pressure, and pulse pressure with mortality after adjustment (fig 1); however, the associations were not statistically significant. Based on the estimated parameters of penalised splines after adjustment, the minimum mortality was around $80 \mathrm{~mm} \mathrm{Hg}, 90 \mathrm{~mm} \mathrm{Hg}$, and $57.5 \mathrm{~mm} \mathrm{Hg}$ for diastolic blood pressure, mean arterial pressure, and pulse pressure, respectively (fig 1).

Unlike with systolic blood pressure, we were unable to identify the two other points with statistically significant differences in all cause mortality compared with study participants having $80 \mathrm{~mm} \mathrm{Hg}$ diastolic blood pressure, $90 \mathrm{~mm} \mathrm{Hg}$ mean arterial pressure, and $57.5 \mathrm{~mm} \mathrm{Hg}$ pulse pressure (fig 1). Thus, in line with previous publications, we defined these two points (for classifying lower, middle, and higher groups) as $70 \mathrm{~mm}$ $\mathrm{Hg}$ and $90 \mathrm{~mm} \mathrm{Hg}$ for diastolic blood pressure, $80 \mathrm{~mm}$
$\mathrm{Hg}$ and $100 \mathrm{~mm} \mathrm{Hg}$ for mean arterial pressure, and 50 $\mathrm{mm} \mathrm{Hg}$ and $65 \mathrm{~mm} \mathrm{Hg}$ for pulse pressure. Accordingly, considering blood pressure as a continuous variable, we stratified the participants into three categories (lower, middle, and higher) based on the Cox models with penalised splines (systolic blood pressure $<107$, 107-154, and $>154 \mathrm{~mm} \mathrm{Hg}$, diastolic blood pressure $<70,70-90$, and $>90 \mathrm{~mm} \mathrm{Hg}$, mean arterial pressure $<80,80-100$, and $>100 \mathrm{~mm} \mathrm{Hg}$, and pulse pressure $<50,50-65$, and $>65 \mathrm{~mm} \mathrm{Hg}) .{ }^{36-38}$

We then used the Cox proportional hazards models with and without the above covariates to estimate

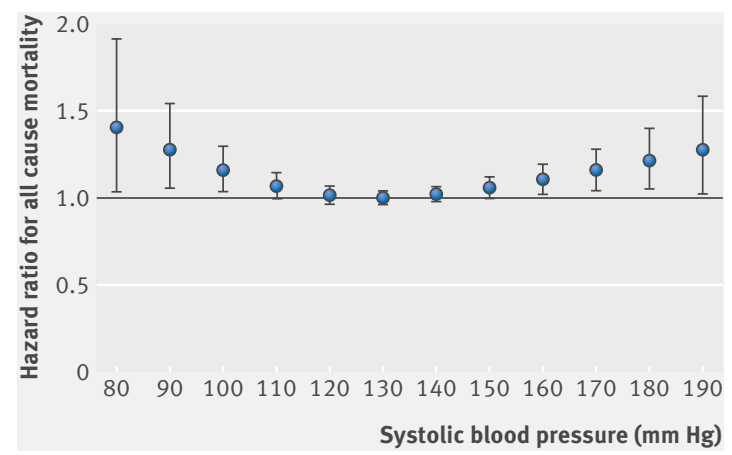

Fig 2 | Hazard ratio $(95 \% \mathrm{Cl})$ for three year all cause mortality at different levels of systolic blood pressure (80-190 mm Hg) in Cox models with penalised splines after adjustment (129 $\mathrm{mm} \mathrm{Hg}$ reference), in study population of Chinese oldest old people 
hazard ratios and 95\% confidence intervals for systolic blood pressure, diastolic blood pressure, mean arterial pressure, or pulse pressure as categorical variables. We also implemented Cox models with penalised splines to assess the associations of continuous systolic blood pressure with cardiovascular and non-cardiovascular mortality. Adjusting for the above demographic and biological covariates, we used Cox proportional hazards models to assess the association between categorical systolic blood pressure and cause specific mortality.

\section{Sensitivity and subgroup analyses}

To clarify the role of participants lost to follow-up in the associations, we did sensitivity analyses for such participants censored at two time points: baseline ( 0 years) and the midpoint of follow-up (1.5 years). To examine the possibility that excessively higher or lower blood pressure values could have been caused by acute disease resulting in increased mortality, we also conducted sensitivity analyses by excluding deaths in the first year.

Some socioeconomic factors, functional status, and morbidity could confound the association of blood pressure with mortality. Thus, we investigated interactions between these factors and blood pressure, and we conducted subgroup analyses among:

- Octogenarians, nonagenarians, and centenarians

- Urban and rural residents

- Participants in marriage and not in marriage

- Participants with and without comorbidities

- Participants with and without a self reported hypertension history

- Participants taking or not taking anti-hypertensive treatment

- Participants with and without restrictions on activities of daily living

- Robust, pre-frail, and frail participants.

We used SAS version 9.3 (SAS Institute) to conduct statistical analyses and $R$ version 3.4.2 ( $R$ foundation for Statistical Computing) to conduct Cox models with penalised splines.

\section{Patient involvement}

None of the participants was involved in the questionnaire design, biological measurements, or outcome measures; they were likewise not involved in the design, recruitment, and implementation of the study. Furthermore, all participants or their relatives were informed of the systolic and diastolic blood pressure results and use of the data for research in this study. There were no plans to disseminate the study results to participants.

\section{Results}

\section{Participant characteristics}

The mean participant age was 92.1 years at baseline; $57.4 \%$ (2675/4658) were female. During the followup of three years, 1997 participants died and 2414 survived (mortality rate $44.2 \%$; table 1 and online supplementary materials).

\section{Association of blood pressure with all cause mortality}

The results of the Cox models with penalised splines revealed $\mathrm{U}$ shaped associations of systolic blood pressure $(\mathrm{P}<0.001)$, mean arterial pressure $(\mathrm{P}=0.002)$, and pulse pressure $(\mathrm{P}=0.002)$ with three year all cause mortality. We saw no significant linear $(\mathrm{P}=0.38)$ or non-linear $(\mathrm{P}=0.12)$ associations between diastolic blood pressure and mortality before adjustment. We identified the inflection points of the $U$ shaped curve, indicating minimum mortality risk, at $143.5 \mathrm{~mm} \mathrm{Hg}$ for systolic blood pressure, $101 \mathrm{~mm} \mathrm{Hg}$ for mean arterial pressure, and $66 \mathrm{~mm} \mathrm{Hg}$ for pulse pressure (fig S3).

However, after adjustment for confounding factors, the $U$ shaped association with three year all cause mortality disappeared for mean arterial pressure $(\mathrm{P}=0.49)$ and pulse pressure $(\mathrm{P}=0.14)$, but remained for systolic blood pressure $(\mathrm{P}=0.035)$. The systolic blood pressure value that conferred the minimum mortality risk was $129 \mathrm{~mm} \mathrm{Hg}$ (fig 1, fig 2). Compared with participants with value of $129 \mathrm{~mm} \mathrm{Hg}$, those with a lower $(<107 \mathrm{~mm} \mathrm{Hg})$ or higher $(>154 \mathrm{~mm} \mathrm{Hg})$ value had a higher mortality risk. Compared with $129 \mathrm{~mm}$ $\mathrm{Hg}$, systolic blood pressure values of 107-154 mm $\mathrm{Hg}$ did not significantly predict higher mortality risk. Before the inflection point of systolic blood pressure at $129 \mathrm{~mm} \mathrm{Hg}$, risk of all cause mortality fell with increasing systolic blood pressure (hazard ratio 1.47 (95\% confidence interval 1.01 to 2.17 ) at $75 \mathrm{~mm} \mathrm{Hg}$, 1.41 (1.03 to 1.93 ) at $80 \mathrm{~mm} \mathrm{Hg}, 1.29$ (1.06 to 1.56) at $90 \mathrm{~mm} \mathrm{Hg}, 1.16$ (1.03 to 1.31 ) at $100 \mathrm{~mm} \mathrm{Hg}$, and 1.08 (1.01 to 1.17$)$ at $106 \mathrm{~mm} \mathrm{Hg}$ ). After the inflection point, risk of all cause mortality rose with increasing systolic blood pressure (1.08 (1.01 to 1.17) at $155 \mathrm{~mm}$ $\mathrm{Hg}, 1.10$ (1.01 to 1.20$)$ at $160 \mathrm{~mm} \mathrm{Hg}, 1.15$ (1.03 to 1.29) at $170 \mathrm{~mm} \mathrm{Hg}, 1.21$ (1.03 to 1.45$)$ at $180 \mathrm{~mm} \mathrm{Hg}$, and 1.27 (1.02 to 1.58 ) at $190 \mathrm{~mm} \mathrm{Hg}$; fig 2).

To compare the ranges of blood pressure with mortality risk, we analysed Cox proportional hazards models with the middle range of blood pressure as the reference category. Compared with the middle range of systolic blood pressure or pulse pressure values, lower and higher values were significantly associated with a greater mortality risk after adjustment (systolic blood pressure: hazard ratio 1.30 (95\% confidence interval 1.11 to 1.53 ) for lower group, 1.16 (1.02 to 1.30) for higher group; pulse pressure: 1.13 (1.02 to 1.25) and 1.15 (1.02 to 1.29); table 2). After conducting sensitivity analyses, the $U$ shaped associations of systolic blood pressure and pulse pressure with mortality remained when participants lost to followup were censored at 1.5 years, all participants lost to follow-up were removed, or participants who died in the first year were excluded (table 2).

Association of systolic blood pressure with all cause mortality in subgroups

We found significant interactions between systolic blood pressure and age group (octogenarians, nonagenarians, and centenarians, $\mathrm{P}<0.001$ ), comorbidities $(\mathrm{P}=0.02)$, functioning in activities of 


\begin{tabular}{|c|c|c|c|c|}
\hline Characteristics & Decedents $(n=1997)$ & Survivors $(n=2414)^{*}$ & Lost to follow-up $(n=247) \dagger$ & Total $(n=4658)$ \\
\hline \multicolumn{5}{|l|}{ Sex } \\
\hline Men & $833(41.7)$ & $1052(43.6)$ & $149(60.3)$ & $1983(42.6)$ \\
\hline Women & $1164(58.3)$ & $1362(56.4)$ & $98(39.7)$ & $2675(57.4)$ \\
\hline Age (year) $\ddagger$ & $94.7(7.3)$ & 89.8 (7.0), $P<0.01$ & 93.5 (8.0), $P<0.01$ & $92.1(7.6)$ \\
\hline Education (years) $\ddagger$ & $1.5(3.0)$ & $1.8(3.2), P<0.01$ & 2.9 (4.4), $P<0.01$ & $1.8(3.2)$ \\
\hline \multicolumn{5}{|l|}{ Marital status } \\
\hline In marriage & $348(17.4)$ & 693 (28.7), $P<0.01$ & $52(21.1), P<0.01$ & $1093(23.5)$ \\
\hline Not in marriage & $1649(82.6)$ & $1721(71.3)$ & $195(78.9)$ & $3565(76.5)$ \\
\hline \multicolumn{5}{|l|}{ Residence } \\
\hline Urban & $395(19.8)$ & $475(19.7)$ & 134 (54.3), $P<0.01$ & $1004(21.5)$ \\
\hline Rural & $1602(80.2)$ & $1939(80.3)$ & $113(45.7)$ & $3654(78.5)$ \\
\hline \multicolumn{5}{|l|}{ Economic income } \\
\hline High & $307(15.4)$ & 506 (21.0), $P<0.01$ & $43(17.4), P<0.01$ & $856(18.4)$ \\
\hline Medium or low & $1690(84.6)$ & $1908(79.0)$ & $204(82.6)$ & $3802(81.6)$ \\
\hline Current smoking practice & $270(13.5)$ & 421 (17.4), $P<0.01$ & 27 (10.9), $P<0.01$ & $718(15.4)$ \\
\hline Alcohol consumption habits & $276(14.0)$ & 417 (17.3), $P<0.01$ & $36(14.6)$ & $731(15.7)$ \\
\hline Cognitive impairment & $1291(64.7)$ & 917 (38.0), $P<0.01$ & 132 (53.4), $P<0.01$ & $2340(50.2)$ \\
\hline Restriction on activities of daily living & $1049(52.5)$ & 617 (25.6), $P<0.01$ & 119 (48.2), $P<0.01$ & $1785(38.3)$ \\
\hline Poor visual function & $782(39.2)$ & $573(23.7), P<0.01$ & $62(25.1), P<0.01$ & $1417(30.4)$ \\
\hline \multicolumn{5}{|l|}{ Frailty } \\
\hline Robust & $535(26.8)$ & 1219 (50.5), $P<0.01$ & 101 (40.9), $P<0.01$ & $1855(39.8)$ \\
\hline Pre-frailty & $783(39.2)$ & $868(36.0)$ & $79(32.0)$ & $1730(37.1)$ \\
\hline Frailty & $679(34.0)$ & $327(13.5)$ & $67(27.1)$ & $1073(23.1)$ \\
\hline Self reported hypertension history & $478(23.9)$ & $662(27.4), P<0.01$ & $55(22.2), P<0.01$ & $1195(25.7)$ \\
\hline Body mass index $\neq$ & $19.8(3.5)$ & $20.9(3.5), P<0.01$ & $20.3(3.6)$ & $20.4(3.5)$ \\
\hline Central obesity & $669(33.5)$ & 1037 (43.0), $P<0.01$ & 106 (43.0), $P<0.01$ & $1812(38.9)$ \\
\hline Diabetes mellitus & $62(3.1)$ & $76(3.2)$ & $6(2.4)$ & $144(3.1)$ \\
\hline Cardiovascular disease & $244(12.2)$ & $295(12.2)$ & $43(17.4), P<0.01$ & $582(12.5)$ \\
\hline Stroke and cerebrovascular disease & $169(8.5)$ & $146(6.1), P<0.01$ & $33(13.4), P<0.05$ & $348(7.5)$ \\
\hline Respiratory disease & $281(14.1)$ & $298(12.3)$ & $33(13.4)$ & $612(13.1)$ \\
\hline Cancer & $18(0.9)$ & $17(0.7)$ & $4(1.6)$ & $39(0.8)$ \\
\hline \multicolumn{5}{|l|}{ Comorbidity } \\
\hline 0 & $1385(69.4)$ & 1762 (73.0), $P<0.01$ & 154 (62.4), $P<0.01$ & $3301(70.9)$ \\
\hline$\geq 1$ & $612(30.6)$ & $652(27.0)$ & $93(37.6)$ & $1357(29.1)$ \\
\hline Systolic blood pressure $(\mathrm{mm} \mathrm{Hg}) \ddagger$ & $134.3(21.2)$ & 136.0 (19.3), $P<0.01$ & $130.6(19.2)$ & $135.0(20.2)$ \\
\hline Diastolic blood pressure $(\mathrm{mm} \mathrm{Hg}) \ddagger$ & $79.2(12.2)$ & $79.6(11.4)$ & $78.4(13.7)$ & $79.4(11.8)$ \\
\hline Mean arterial pressure $(\mathrm{mm} \mathrm{Hg}) \neq$ & $97.6(13.5)$ & 98.4 (12.3), $P<0.05$ & $95.8(14.0)$ & $97.9(12.9)$ \\
\hline Pulse pressure $(\mathrm{mm} \mathrm{Hg}) \ddagger$ & $55.0(17.3)$ & 56.4 (16.3), $P<0.01$ & $52.2(15.4)$ & $55.6(16.7)$ \\
\hline \multicolumn{5}{|l|}{ Systolic blood pressure classification } \\
\hline Lower $(<107$ mm Hg) & $176(8.8)$ & 118 (4.9), $P<0.01$ & $17(6.9)$ & $311(6.7)$ \\
\hline Middle (107-154 mm Hg) & $1484(74.3)$ & $1888(78.2)$ & $201(81.4)$ & $3573(76.7)$ \\
\hline Higher (>154 mm Hg) & $337(16.9)$ & $408(16.9)$ & $29(11.7)$ & $774(16.6)$ \\
\hline Antihypertensive treatment & $108(59.3)$ & $72(45.9), P<0.05$ & - & $180(53.1)$ \\
\hline
\end{tabular}

daily living $(\mathrm{P}<0.001)$, and frailty $(\mathrm{P}<0.001)$. We observed a marginally significant interaction with self reported hypertension history $(\mathrm{P}=0.08)$, and non-significant interactions with residence $(\mathrm{P}=0.20)$ and marital status $(\mathrm{P}=0.14)$. Significant $U$ shaped associations of systolic blood pressure with three year all cause mortality were evident for octogenarians and nonagenarians but not for centenarians. For centenarians, we found a similar U shaped trend, but it was not significant $(\mathrm{P}=0.13)$, which could be due to the relatively limited study sample. We observed U shaped associations of systolic blood pressure with mortality among participants in both rural and urban areas. Based on the supplementary phone interview, we found no association between systolic blood pressure and mortality according to whether participants were taking antihypertensive treatment or not.
Association of systolic blood pressure with cause specific mortality

Among 1088 participants with an ascertained cause of death, 270 (24.8\%) died from cardiovascular disease and 818 (75.2\%) died from non-cardiovascular causes. Cause specific analyses showed linear associations between systolic blood pressure and cardiovascular death $(\mathrm{P}<0.001)$ and non-cardiovascular death $(\mathrm{P}<0.001$; fig 3). Each increment of $10 \mathrm{~mm} \mathrm{Hg}$ in systolic blood pressure corresponded to an $11 \%$ increase in cardiovascular mortality (adjusted hazard ratio 1.11 (95\% confidence interval 1.05 to 1.18$)$ ), and a $5 \%$ decrease in risk of non-cardiovascular mortality (0.95 (0.92 to 0.99); table 3).

Compared with middle range systolic blood pressure (107-154 mm Hg), higher values (>154 mm Hg) predicted a higher risk of cardiovascular mortality 


\begin{tabular}{|c|c|c|c|c|c|c|c|}
\hline \multirow[b]{2}{*}{$\begin{array}{l}\text { Variables } \\
\text { and value } \\
\text { groups }\end{array}$} & \multirow[b]{2}{*}{ Decedents (No) } & \multirow[b]{2}{*}{$\begin{array}{l}\text { Mortality rate } \\
(\% ; 95 \% \mathrm{Cl})\end{array}$} & \multicolumn{2}{|l|}{ Hazard ratio $(95 \% \mathrm{Cl})$} & \multicolumn{3}{|l|}{ Sensitivity analyses } \\
\hline & & & Unadjusted & Adjusted‡ & $\begin{array}{l}\text { Censoring at } 1.5 \text { years } \\
\text { of participants lost to } \\
\text { follow-up }\end{array}$ & $\begin{array}{l}\text { Removal of all } \\
\text { participants lost to } \\
\text { follow-up }\end{array}$ & $\begin{array}{l}\text { Exclusion of } \\
\text { participants who } \\
\text { died in the first year }\end{array}$ \\
\hline \multicolumn{8}{|c|}{ Systolic blood pressure } \\
\hline $\begin{array}{l}\text { Lower (<107 } \\
\mathrm{mm} \mathrm{Hg})\end{array}$ & 176 & $58.4(52.6$ to 64.2$)$ & $1.57(1.35$ to 1.84$) \dagger$ & $1.30(1.11$ to 1.53$) \dagger$ & $1.27(1.08$ to 1.48$) \dagger$ & $1.27(1.08$ to 1.48$) \dagger$ & 1.38 (1.14 to 1.67$) \dagger$ \\
\hline $\begin{array}{l}\text { Middle (107- } \\
154 \mathrm{~mm} \mathrm{Hg})\end{array}$ & 1484 & $42.9(41.3$ to 44.6$)$ & 1.00 (reference) & 1.00 (reference) & 1.00 (reference) & 1.00 (reference) & 1.00 (reference) \\
\hline $\begin{array}{l}\text { Higher (>154 } \\
\mathrm{mm} \mathrm{Hg})\end{array}$ & 337 & $44.6(41.0$ to 48.1$)$ & $1.04(0.93$ to 1.17$)$ & $1.16(1.02 \text { to } 1.30)^{\star}$ & $1.15(1.02 \text { to } 1.29)^{\star}$ & $1.15(1.02 \text { to } 1.29)^{\star}$ & $1.17(1.02 \text { to } 1.36)^{\star}$ \\
\hline \multicolumn{8}{|c|}{ Diastolic blood pressure } \\
\hline $\begin{array}{l}\text { Lower }(<70 \\
\mathrm{mm} \mathrm{Hg})\end{array}$ & 367 & $48.5(44.9$ to 52.1$)$ & $1.17(1.04 \text { to } 1.31)^{\star}$ & $1.02(0.90$ to 1.14$)$ & $1.04(0.94$ to 1.16$)$ & $1.07(0.96$ to 1.19$)$ & $0.99(0.88$ to 1.14$)$ \\
\hline $\begin{array}{l}\text { Middle (70- } \\
90 \mathrm{~mm} \mathrm{Hg})\end{array}$ & 1254 & $43.3(41.5$ to 45.1$)$ & 1.00 (reference) & 1.00 (reference) & 1.00 (reference) & 1.00 (reference) & 1.00 (reference) \\
\hline $\begin{array}{l}\text { Higher (>90 } \\
\mathrm{mm} \mathrm{Hg})\end{array}$ & 376 & $43.7(40.3$ to 47.1$)$ & $1.02(0.90$ to 1.14$)$ & 1.01 (0.90 to 1.13$)$ & $1.02(0.91$ to 1.15$)$ & $1.03(0.92$ to 1.16$)$ & 0.96 (0.83 to 1.11$)$ \\
\hline \multicolumn{8}{|c|}{ Mean arterial pressure } \\
\hline $\begin{array}{l}\text { Lower }(<80 \\
\mathrm{mm} \mathrm{Hg})\end{array}$ & 165 & $52.3(46.5$ to 58.1$)$ & $1.28(1.08$ to 1.51$) \dagger$ & $1.08(0.89$ to 1.30$)$ & $1.13(0.97$ to 1.34$)$ & 1.13 (0.98 to 1.33$)$ & $1.13(0.92$ to 1.40$)$ \\
\hline $\begin{array}{l}\text { Middle (80- } \\
100 \text { mm Hg) }\end{array}$ & 1041 & $46.0(42.4$ to 49.6$)$ & 1.00 (reference) & 1.00 (reference) & 1.00 (reference) & 1.00 (reference) & 1.00 (reference) \\
\hline $\begin{array}{l}\text { Higher (>100 } \\
\mathrm{mm} \mathrm{Hg})\end{array}$ & 791 & $43.9(41.6$ to 46.1$)$ & $1.02(0.93$ to 1.11$)$ & $1.08(0.95$ to 1.23$)$ & 1.07 (0.98 to 1.18$)$ & 1.09 (0.99 to 1.19$)$ & 1.08 (0.97 to 1.22$)$ \\
\hline \multicolumn{8}{|c|}{ Pulse pressure } \\
\hline $\begin{array}{l}\text { Lower }(<50 \\
\mathrm{mm} \mathrm{Hg})\end{array}$ & 810 & $48.3(45.9$ to 50.7$)$ & 1.21 (1.10 to 1.34$) \dagger$ & $1.13(1.02 \text { to } 1.25)^{\star}$ & $1.13(1.02 \text { to } 1.25)^{\star}$ & $1.14(1.03 \text { to } 1.26)^{\star}$ & $1.14(1.01 \text { to } 1.29)^{\star}$ \\
\hline $\begin{array}{l}\text { Middle (50- } \\
65 \mathrm{~mm} \mathrm{Hg})\end{array}$ & 731 & 41.5 (39.1 to 43.9) & 1.00 (reference) & 1.00 (reference) & 1.00 (reference) & 1.00 (reference) & 1.00 (reference) \\
\hline $\begin{array}{l}\text { Higher (>65 } \\
\mathrm{mm} \mathrm{Hg})\end{array}$ & 456 & $42.2(39.4$ to 45.3$)$ & $1.03(0.92$ to 1.16$)$ & $1.15(1.02 \text { to } 1.29)^{\star}$ & $1.15(1.02 \text { to } 1.29)^{\star}$ & $1.14(1.01 \text { to } 1.28)^{\star}$ & $1.15(1.00 \text { to } 1.32)^{\star}$ \\
\hline \multicolumn{8}{|c|}{$\begin{array}{l}\text { *P }<0.05 . \\
+\mathrm{P}<0.01 . \\
\text { fCox proportional hazards models were applied, with adjustment for sex, age (as linear term), marital status, educational background (as linear term), residence, economic income, current } \\
\text { smoking, current alcohol consumption, cognitive impairment, restriction on activities of daily living, poor visual function, body mass index (as linear term), central obesity, diabetes mellitus, } \\
\text { cardiovascular disease, stroke and other cerebrovascular diseases, respiratory disease, cancer, and frailty. }\end{array}$} \\
\hline
\end{tabular}

(adjusted hazard ratio 1.51 (95\% confidence interval 1.12 to 2.02$)$ ); lower values $(<107 \mathrm{~mm} \mathrm{Hg})$ did not significantly predict cardiovascular mortality risk (0.91 (0.54 to 1.56)). However, lower values predicted a higher risk of non-cardiovascular mortality (1.58 (1.26 to 1.98)); higher values did not significantly predict non-cardiovascular mortality risk (0.97 (0.79 to 1.19); table 3). These results indicated that a higher systolic blood pressure predicted a higher risk of cardiovascular mortality, whereas lower values predicted a higher risk of non-cardiovascular mortality in the study participants.

\section{Discussion}

In this community based prospective study, after adjustment for important identified confounders, systolic blood pressure presented a U shaped association with all cause mortality among a group of oldest old people in China. Specifically, higher values of systolic blood pressure predicted a higher risk of cardiovascular mortality; lower values predicted a higher risk of non-cardiovascular mortality. After we explored this association in different subgroups of participants, the results further supported the $U$ shaped association between systolic blood pressure and mortality.

\section{Comparison with other studies}

Individuals older than 80 years have rarely been a target population for investigating the relations of blood pressure with cause specific mortality and all cause mortality. Previous clinical or epidemiological studies have reported conflicting results regarding this association. ${ }^{3-19}$ Most observational studies have found that high blood pressure predicted higher mortality risk, ${ }^{3-11}$ although some observational studies reported no relation of blood pressure with mortality. ${ }^{15} 16$

The findings of the present study has been relatively similar to those from previous investigations. ${ }^{12-14}$ In a three year follow-up of 724 participants aged 84-88 years in Finland, participants with an systolic blood pressure of 140-169 mm Hg or diastolic blood pressure of $70-99 \mathrm{~mm} \mathrm{Hg}$ had the lowest mortality risk. ${ }^{12} \mathrm{~A}$ study of 348 people aged 85 years and older in Sweden identified a $\mathrm{U}$ shaped association of systolic blood pressure with mortality; after inclusion of systolic blood pressure as the squared term in the adjusted Cox regression, the optimal value was found to be 164.2 $\mathrm{mm} \mathrm{Hg}$ for this age group. ${ }^{13}$ Among 1088 Americans aged 85 years and older, higher systolic blood pressure was found to predict improved survival during a six year follow-up; a J shaped association was seen after quadratic transformation of systolic and diastolic blood pressure. ${ }^{14}$ However, none of those findings of a J or U shaped association was based on Cox models with penalised splines, which were able to examine a non-parametric (non-linear or linear) association of blood pressure with mortality. 


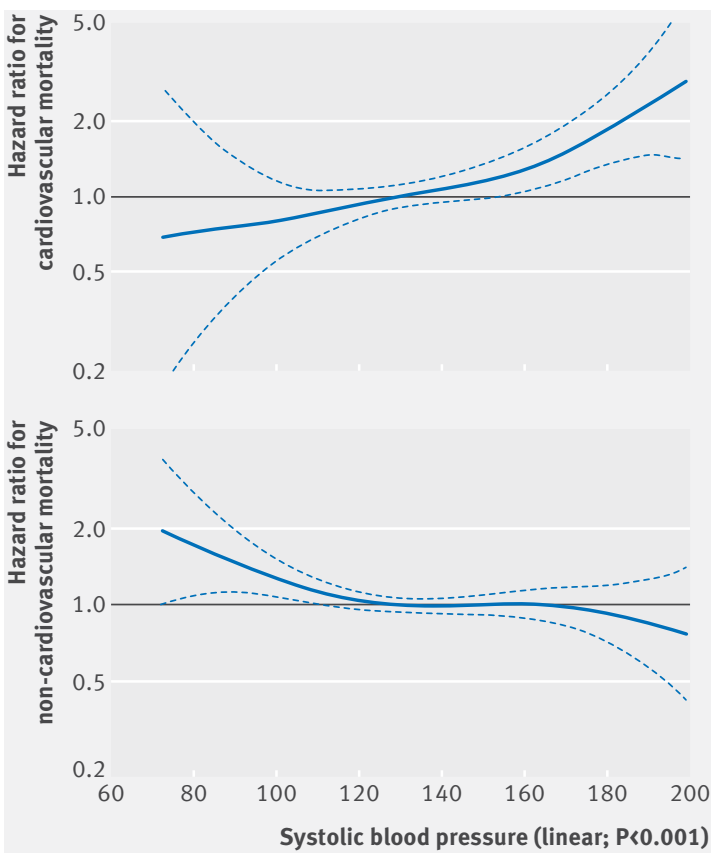

Fig 3 | Associations of systolic blood pressure with three year cardiovascular and non-cardiovascular mortality risk in study population of Chinese oldest old people, in Cox models with penalised splines after adjustment. Lines=estimated hazard ratio of systolic blood pressure (129 mm Hg reference) for three year cardiovascular and non-cardiovascular mortality; dotted lines $=95 \%$ confidence intervals

Compared with previous studies, ${ }^{12-14}$ the present investigation found lower levels of systolic and diastolic blood pressure in the oldest old study sample. This difference could have been due to our oversampling of nonagenarians and centenarians. In this survey, centenarians, one nearby octogenarian, and one nearby nonagenarian in each of the selected counties were interviewed. This sample was therefore different from a population with a naturally occurring age distribution, because the participants was relatively older (92.1 years). Accordingly, our participants could have had lower blood pressure because blood pressure declines with age after 75 years. ${ }^{39}$

The association of blood pressure with mortality remains unclear. In the ageing process, functional and organic changes in the cardiovascular system occur in response to metabolic alterations; those changes could affect blood pressure. In addition, people who survive to age 80 could be selected healthy individuals. It is possible that middle aged or younger elderly people with low or high blood pressure have a higher mortality risk; the oldest old individuals in our study could have been a select population ${ }^{3}$ as a result of regression to the mean. In our study, higher systolic blood pressure predicted a higher risk of cardiovascular mortality, and lower systolic blood pressure predicted a higher risk of non-cardiovascular mortality; this finding probably explains the $U$ shaped association of systolic blood pressure with all cause mortality.

\section{Lower blood pressure and mortality}

The most likely explanation for increased mortality risk in participants with lower systolic blood pressure was chronic disease-eg, cardiovascular disease ${ }^{40}$ (cardiac failure or ischaemic heart disease), cancer or other wasting diseases, ${ }^{41}$ or poor functional status or frailty. ${ }^{42}$ The lower values of systolic blood pressure observed in our participants could be due to increasing vascular frailty, or related to deteriorating health with ageing. In previous investigations of participants aged 85 years and older, the association of lower blood pressure with greater mortality disappeared after adjustment for poor health status. ${ }^{43}$ But in the present study, the association remained robust even after controlling for health status or functional status. In the subgroup analyses, the $U$ shaped association persisted in participants without comorbidities, in those who were able to perform activities of daily living adequately, and in pre-frail participants. These findings indicated that the association of lower systolic blood pressure with increased mortality cannot be entirely explained by chronic illnesses, poor functional status, or frailty.

The association of lower blood pressure with greater mortality risk has been shown to be relevant only in the short term. ${ }^{44}$ As previous studies have shown, ${ }^{45} 46$ after exclusion of death in the first year, the relation between lower systolic blood pressure and increased mortality risk remained. This finding suggested that lower systolic blood pressure being predictive of higher risks of non-cardiovascular mortality and all cause

\begin{tabular}{|c|c|c|c|c|c|c|}
\hline \multirow[b]{3}{*}{ Variables } & \multicolumn{6}{|l|}{ Hazard ratio $(95 \% \mathrm{Cl})$} \\
\hline & \multicolumn{2}{|l|}{ Cardiovascular mortality } & \multicolumn{2}{|c|}{ Non-cardiovascular mortality } & \multicolumn{2}{|l|}{ All cause mortality } \\
\hline & Unadjusted & Adjusted & Unadjusted & Adjusted & Unadjusted & Adjusted \\
\hline \multicolumn{7}{|c|}{ Systolic blood pressure as continuous variable } \\
\hline Each $10 \mathrm{~mm} \mathrm{Hg}$ increment & 1.10 (1.04 to 1.116$) \ddagger$ & $1.11(1.05$ to 1.18$) \neq$ & $0.91(0.88$ to 0.94$) \ddagger$ & $0.95(0.92$ to 0.99$) \dagger$ & 0.97 (0.95 to 0.99)‡ & 1.01 (0.98 to 1.03$)$ \\
\hline \multicolumn{7}{|c|}{ Systolic blood pressure as categorical variable } \\
\hline Lower $(<107 \mathrm{~mm} \mathrm{Hg})$ & $0.96(0.56$ to 1.67$)$ & $0.91(0.54$ to 1.56$)$ & $1.93(1.55$ to 2.41$) \ddagger$ & $1.58(1.26$ to 1.98$) \neq$ & $1.57(1.35$ to 1.84$) \neq$ & $1.30(1.11$ to 1.53$) \neq$ \\
\hline Middle (107-154 mm Hg) & 1.00 (reference) & 1.00 (reference) & 1.00 (reference) & 1.00 (reference) & 1.00 (reference) & 1.00 (reference) \\
\hline Higher $(>154$ mm Hg) & $1.47(1.10$ to 1.96$) \neq$ & $1.51(1.12$ to 2.02$) \neq$ & $0.84(0.69$ to 1.03$)$ & $0.97(0.79$ to 1.19$)$ & 1.04 (0.93 to 1.17$)$ & $1.16(1.02$ to 1.30$) \dagger$ \\
\hline
\end{tabular}


mortality was more complex than a simple fall in blood pressure approaching death.

\section{Higher blood pressure and mortality}

The evidence for treating patients 80 years and older has long been debated; epidemiological studies have detected the association of higher blood pressure with increased mortality risk for this age group. ${ }^{2-11}$ In the present study, compared with a middle value range of systolic blood pressure, a higher value $(>154 \mathrm{~mm}$ $\mathrm{Hg}$ ) predicted a higher risk of all cause mortality and cardiovascular mortality, which was in accordance with other investigations. ${ }^{17}$ 47-50

It has been found that treatment of hypertension reduced stroke while possibly increasing all cause mortality. ${ }^{47}$ A study of 3845 patients older than 80 years in Europe, Australasia, Tunisia, and China showed a reduction in mortality with hypertension treatment. ${ }^{48}$ One large meta-analysis showed that a high systolic blood pressure predicted a higher risk of mortality for any age group, including oldest old people; however, the relation weakened considerably with ageing. ${ }^{17}$ Recent guidelines on antihypertensive treatment for older individuals with hypertension could be beneficial, including those aged over 80 years. ${ }^{49} 50$

\section{Associations of mean arterial pressure and pulse pressure with mortality}

The same level of attention to systolic and diastolic blood pressure has not been given to pulse pressure. However, studies have suggested that pulse pressure was more sensitive for mortality predication, with increased aortic regurgitation or aortic stiffness with ageing among elderly people aged 65 years and older. ${ }^{5152}$ Very few studies have focused on the association of mortality with pulse pressure, and those few studies have found no significant associations in oldest old people. ${ }^{7}$ The present investigation showed that both lower and higher pulse pressure predicted poor survival, suggesting that pulse pressure-and not just systolic and diastolic blood pressure-should be considered in oldest old individuals.

To our knowledge, no previous reports have focused on the role of mean arterial pressure in oldest old people-even though studies have revealed that it is likely to be a more accurate predictor than other blood pressure indexes. ${ }^{53}$ Our study showed a U shaped association of mean arterial pressure with mortality in Cox models with penalised splines before adjustment; however, the association was not evident on further analysis after adjustment.

\section{Strengths and limitations}

Our study had a large sample size to assess the role of blood pressure in all cause mortality and cause specific mortality among community based oldest old people in China. This large sample allowed robust conclusions to be drawn with respect to octogenarians, nonagenarians, and centenarians. This study performed Cox models with penalised splines to investigate potential non-linear associations, and our methodology allowed the optimal blood pressure to be identified. This study also focused on the association of mean arterial pressure with mortality among oldest old individuals. Furthermore, the study participation rate was very high $(94.7 \%)$, indicating that obtaining death information was relatively complete.

This study had several limitations. Firstly, no corrections were conducted in multiple comparisons, which could have increased the possibility of type 1 errors. However, the $U$ shaped association might be a true association because it was consistently detected for systolic blood pressure and pulse pressure after adjustment. Secondly, blood pressure in this study was measured at one time only; however, the variability between the two blood pressure measurements at baseline was small. Thirdly, most of the clinical diseases adjusted as confounding factors were self reported; participants were asked whether diseases had been diagnosed by a doctor. Furthermore, we obtained information on cause specific death for only $54 \%$ of decedents. It was difficult to determine the cause of death for people aged 80 years and older, who were likely to have various chronic diseasesespecially among those who died at home and not in hospital. Finally, this study included only people aged 80 years and older; the findings cannot therefore be generalised to younger populations.

\section{Conclusions}

In this longitudinal, community based prospective study among oldest old people in China, systolic blood pressure showed a U shaped association with three year all cause mortality. This association is likely to be explained by the finding that higher values of systolic blood pressure predicted a higher risk of cardiovascular mortality, and lower values of systolic blood pressure predicted a higher risk of non-cardiovascular mortality. The present paradigm of "the lower the better" in blood pressure regulation does not apply to oldest old people; practitioners and researchers should be aware that the notion of so-called normal blood pressure might need to be revisited after age 80 years. Present guidelines for blood pressure management have been proposed to be applied individually and cautiously with this population. Specific guidelines might need to be explored for blood pressure management for individuals older than 80 years with different blood pressure levels.

We thank staff at the provincial and county Centers for Disease Control and Prevention for carrying out the fieldwork; the 4658 study participants; and Chen Mao of Southern Medical University, Jin-Qiu Yuan at the Chinese University of Hong Kong, and Hui-Ying Liang and Zhi-Hao Li of the Guangzhou Women and Children's Medical Center for their work on the manuscript revisions.

Contributors: $Y-B L, X G$, and Z-XY contributed to the concept and data analysis of the manuscript. $\mathrm{H}-\mathrm{SC}$ and J-SL helped to implement the survey. X-MS and YZ designed the survey. MSB, VBK, and T-TL helped to conduct the data analysis. X-MS was responsible for accuracy of data analysis. All authors contributed to the framework construction, results interpretation, manuscript revision, and approved the final version of the manuscript. XMS is guarantor. The corresponding author attests that all listed authors meet authorship criteria and that no others meeting the criteria have been omitted. 
Funding: The Chinese Longitudinal Healthy Longevity Survey, which provided the data analysed in this article, is jointly supported by National Natural Sciences Foundation of China (71233001, 71490732, and 81573247), US National Institute of Ageing (2P01AG031719), United Nations Fund for Population Activities, and a grant from the Claude D Pepper Older Americans Independence Center (5P30 AG028716 from the National Institute of Ageing to VBK). The funders had no role in the study design or implementation; the data collection, management, analysis, and interpretation; the manuscript preparation, review, or approval; or the decision to submit the manuscript for publication.

Competing interests: All authors have completed the ICMJE uniform disclosure form at www.icmje.org/coi_disclosure.pdf and declare: support from the National Natural Sciences Foundation of China, US National Institute of Ageing, United Nations Fund for Population Activities, and Claude D Pepper Older Americans Independence Center for the submitted work; no financial relationships with any organisations that might have an interest in the submitted work in the previous three years; no other relationships or activities that could appear to have influenced the submitted work.

Ethical approval: The biomedical ethics committee of Peking University approved the study (IRB00001052-13074), and all participants or their proxy respondents provided written informed consent.

Data sharing: No additional data available.

The lead author affirms that the manuscript is an honest, accurate, and transparent account of the study being reported; that no important aspects of the study have been omitted; and that any discrepancies from the study as planned (and, if relevant, registered) have been explained.

This is an Open Access article distributed in accordance with the Creative Commons Attribution Non Commercial (CC BY-NC 4.0) license, which permits others to distribute, remix, adapt, build upon this work non-commercially, and license their derivative works on different terms, provided the original work is properly cited and the use is noncommercial. See: http://creativecommons.org/licenses/by-nc/4.0/.

1 Ettehad D, Emdin CA, Kiran A, et al. Blood pressure lowering for prevention of cardiovascular disease and death: a systematic review and meta-analysis. Lancet 2016;387:957-67. doi:10.1016/ S0140-6736(15)01225-8

2 Franklin SS, Gokhale SS, Chow VH, et al. Does low diastolic blood pressure contribute to the risk of recurrent hypertensive cardiovascular disease events? The Framingham Heart Study. Hypertension 2015:65:299-305. doi:10.1161/ HYPERTENSIONAHA.114.04581

3 Rastas S, Pirttilä T, Viramo P, et al. Association between blood pressure and survival over 9 years in a general population aged 85 and older. J Am Geriatr Soc 2006;54:912-8. doi:10.1111/j.1532 5415.2006.00742.x

4 Mattila K, Haavisto M, Rajala S, Heikinheimo R. Blood pressure and five year survival in the very old. Br Med I (Clin Res Ed) 1988;296:887-9. doi:10.1136/bmj.296.6626.887

5 Langer RD, Ganiats TG, Barrett-Connor E. Factors associated with paradoxical survival at higher blood pressures in the very old. Am J Epidemiol 1991;134:29-38. doi:10.1093/oxfordjournals.aje. a115990

6 Weidung B, Boström G, Toots A, et al. Blood pressure, gait speed, and mortality in very old individuals: a population-based cohort study. J Am Med Dir Assoc 2015;16:208-14. doi:10.1016/j.jamda. 2014.09.004

7 Kagiyama S, Takata Y, Ansai T, et al. Does decreased diastolic blood pressure associate with increased mortality in 80-year-old Japanese? Clin Exp Hypertens 2009;31:639-47. doi:10.3109/10641960903407009

8 Langer RD, Ganiats TG, Barrett-Connor E. Factors associated with paradoxical survival at higher blood pressures in the very old. Am J Epidemiol 1991;134:29-38. doi:10.1093/oxfordjournals.aje. a115990

9 van Bemmel T, Gussekloo J, Westendorp RG, Blauw GJ. In a population-based prospective study, no association between high blood pressure and mortality after age 85 years. J Hypertens 2006;24:287-92. doi:10.1097/01.hjh.0000200513.48441.8e

10 Poortvliet RK, Blom IW, de Craen Al, et al. Low blood pressure predicts increased mortality in very old age even without heart failure: the Leiden 85-plus Study. EurJ Heart Fail 2013;15:528-33. doi:10.1093/eurihf/hfs203

11 Badia Farré T, Formiga Perez F, Almeda Ortega J, Ferrer Feliu A, RojasFarreras S, Grupo Octabaix. [Relationship between blood pressure and mortality at 4 years of follow up in a cohort of individuals aged over 80 years]. Med Clin (Barc) 2011:137:97-103.
12 Heikinheimo RJ, Haavisto MV, Kaarela RH, Kanto AJ, Koivunen MJ, Rajala SA. Blood pressure in the very old. J Hypertens 1990;8:361-7. doi:10.1097/00004872-199004000-00010

13 Molander L, Lövheim H, Norman T, Nordström P, Gustafson Y. Lower systolic blood pressure is associated with greater mortality in people aged 85 and older. I Am Geriatr Soc 2008:56:1853-9. doi:10.1111/ j.1532-5415.2008.01948.x

14 Satish S, Freeman DHJr, Ray L, Goodwin JS. The relationship between blood pressure and mortality in the oldest old. I Am Geriatr Soc 2001;49:367-74. doi:10.1046/j.1532-5415.2001.49078.x

15 Kagiyama S, Fukuhara M, Ansai T, et al. Association between blood pressure and mortality in 80-year-old subjects from a populationbased prospective study in Japan. Hypertens Res 2008;31:265-70. doi:10.1291/hypres.31.265

16 Fraser GE, Shavlik DJ. Risk factors for all-cause and coronary heart disease mortality in the oldest-old. The Adventist Health Study. Arch Intern Med 1997;157:2249-58. doi:10.1001/ archinte.1997.00440400099012

17 Lewington S, Clarke R, Qizilbash N, Peto R, Collins R, Prospective Studies Collaboration. Age-specific relevance of usual blood pressure to vascular mortality: a meta-analysis of individual data for one million adults in 61 prospective studies. Lancet 2002;360:1903-13. doi:10.1016/S0140-6736(02)11911-8

18 SHEP Cooperative Research Group. Prevention of stroke by antihypertensive drug treatment in older persons with isolated systolic hypertension. Final results of the Systolic Hypertension in the Elderly Program (SHEP). JAMA 1991;265:3255-64. doi:10.1001/ jama.1991.03460240051027

19 Kostis JB, Davis BR, Cutler J, et al, SHEP Cooperative Research Group. Prevention of heart failure by antihypertensive drug treatment in older persons with isolated systolic hypertension. JAMA 1997:278:212-6. doi:10.1001/jama.1997.03550030052033

20 Bulpitt CJ, Beckett NS, Peters R, et al. Blood pressure contro in the Hypertension in the Very Elderly Trial (HYVET). J Hum Hypertens 2012;26:157-63. doi:10.1038/jhh.2011.10

21 Wright JTJr. Williamson JD, Whelton PK, et al, SPRINT Research Group. A randomized trial of intensive versus standard blood pressure control. N Engl J Med 2015;373:2103-16. doi:10.1056/ NEIMoa1511939

22 Gray R. Flexible Methods for Analyzing Survival Data Using Splines, with Applications to Breast Cancer Prognosis. J Am Stat Assoc 1992:87:942-5110.1080/01621459.1992.10476248.

23 Benetos A, Gautier S, Labat C, et al. Mortality and cardiovascular events are best predicted by low central/peripheral pulse pressure amplification but not by high blood pressure levels in elderly nursing home subjects: the PARTAGE (Predictive Values of Blood Pressure and Arterial Stiffness in Institutionalized Very Aged Population) study. J Am Coll Cardiol 2012;60:1503-11. doi:10.1016/j.jacc.2012.04.055

24 Pastor-Barriuso R, Banegas JR, Damián J, Appel LJ, Guallar E. Systolic blood pressure, diastolic blood pressure, and pulse pressure: an evaluation of their joint effect on mortality. Ann Intern Med 2003:139:731-9 doi:10.7326/0003-4819-139-9200311040-00007

25 Zeng Y, Feng Q, Hesketh T, Christensen K, Vaupel JW. Survival, disabilities in activities of daily living, and physical and cognitive functioning among the oldest-old in China: a cohort study. Lancet 2017;389:1619-29. doi:10.1016/S0140-6736(17)30548-2

26 Qiu L, Sautter J, Gu D. Associations between frequency of tea consumption and health and mortality: evidence from old Chinese. $\mathrm{Br}$ J Nutr 2012;108:1686-97. doi:10.1017/S0007114511007173

27 Lv YB, Yin ZX, Chei CL, et al. Low-density lipoprotein cholesterol was inversely associated with 3-year all-cause mortality among Chinese oldest old: data from the Chinese Longitudinal Healthy Longevity Survey. Atherosclerosis 2015;239:137-42. doi:10.1016 jatherosclerosis. 2015.01.002

28 Ensrud KE, Ewing SK, Taylor BC, et al. Comparison of 2 frailty indexes for prediction of falls, disability, fractures, and death in older women. Arch Intern Med 2008;168:382-9. doi:10.1001/ archinternmed.2007.113

29 Goggins WB, Woo J, Sham A, Ho SC. Frailty index as a measure of biological age in a Chinese population. J Gerontol A Biol Sci Med Sci 2005;60:1046-51. doi:10.1093/gerona/60.8.1046

30 Allison P. Missing data. Sage, 200210.4135/9781412985079.

31 Dupre ME, Gu D, Warner DF, Yi Z. Frailty and type of death among older adults in China: prospective cohort study. BMJ 2009;338:b1175. doi:10.1136/bmj.b1175

32 Eisen EA, Agalliu I, Thurston SW, Coull BA, Checkoway H. Smoothing in occupational cohort studies: an illustration based on penalised splines. Occup Environ Med 2004;61:854-60. doi:10.1136/ oem.2004.013136

33 Malloy El, Spiegelman D, Eisen EA. Comparing measures of model selection for penalized splines in Cox models. Comput Stat Data Anal 2009;53:2605-16. doi:10.1016/j.csda.2008.12.008

34 O'Sullivan F Nonparametric estimation in the Cox model. Ann Stat 1993:21:124-4510.1214/aos/1176349018. 
35 Meira-Machado L, Cadarso-Suárez C, Gude F, Araújo A. smoothHR: an $\mathrm{R}$ package for pointwise nonparametric estimation of hazard ratio curves of continuous predictors. Comput Math Methods Med 2013;2013:745742. doi:10.1155/2013/745742

36 Post Hospers G, Smulders YM, Maier AB, Deeg DJ, Muller M. Relation between blood pressure and mortality risk in an older population: role of chronological and biological age. J Intern Med 2015;277: 488-97. doi:10.1111/joim.12284

37 Sesso HD, Stampfer MJ, Rosner B, et al. Systolic and diastolic blood pressure, pulse pressure, and mean arterial pressure as predictors of cardiovascular disease risk in Men. Hypertension 2000;36:801-7. doi:10.1161/01.HYP.36.5.801

38 Benetos A, Safar M, Rudnichi A, et al. Pulse pressure: a predictor of long-term cardiovascular mortality in a French male population. Hypertension 1997;30:1410-5. doi:10.1161/01.HYP.30.6.1410

39 Langer RD, Criqui MH, Barrett-Connor EL, Klauber MR, Ganiats TG. Blood pressure change and survival after age 75 Hypertension 1993;22:551-9. doi:10.1161/01.HYP.22.4.551

40 van Bemmel T, Holman ER, Gussekloo J, Blauw GJ, Bax JJ, Westendorp RG. Low blood pressure in the very old, a consequence of imminent heart failure: the Leiden 85-plus Study. J Hum Hypertens 2009;23:27-32. doi:10.1038/jhh.2008.79

41 Molander L, Gustafson Y, Lövheim H. Longitudinal associations between blood pressure and dementia in the very old. Dement Geriatr Cogn Disord 2010;30:269-76. doi:10.1159/000320252

42 Clegg A, Young J, Iliffe S, Rikkert MO, Rockwood K. Frailty in elderly people. Lancet 2013;381:752-62. doi:10.1016/S01406736(12)62167-9

43 Boshuizen HC, Izaks GJ, van Buuren S, Ligthart GJ. Blood pressure and mortality in elderly people aged 85 and older: community based study. BMJ 1998;316:1780-4. doi:10.1136/bmj.316.7147.1780

44 Glynn RJ, Field TS, Rosner B, Hebert PR, Taylor JO, Hennekens CH. Evidence for a positive linear relation between blood pressure and mortality in elderly people. Lancet 1995;345:825-9. doi:10.1016/ S0140-6736(95)92964-9

45 Hakala SM, Tilvis RS, Strandberg TE. Blood pressure and mortality in an older population. A 5-year follow-up of the Helsinki Ageing Study. Eur Heart J 1997;18:1019-23. doi:10.1093/oxfordjournals. eurheartj.a015360
46 Sørensen KH, Hilden T. Increased total mortality and decreased functional capacity are associated with low systolic blood pressure among elderly women. Scand J Prim Health Care 1988;6:105-10. doi:10.3109/02813438809009299

47 Bulpitt CJ, Beckett NS, Cooke J, et al, Hypertension in the Very Elderly Trial Working Group. Results of the pilot study for the Hypertension in the Very Elderly Trial. J Hypertens 2003;21:2409-17. doi:10.1097/00004872-200312000-00030

48 Beckett NS, Peters R, Fletcher AE, et al, HYVET Study Group. Treatment of hypertension in patients 80 years of age or older. N Engl J Med 2008;358:1887-98. doi:10.1056/NEJMoa0801369

49 Mancia G, Fagard R, Narkiewicz K, et al, Task Force Members. 2013 ESH/ESC Guidelines for the management of arterial hypertension: the Task Force for the management of arterial hypertension of the European Society of Hypertension (ESH) and of the European Society of Cardiology (ESC). J Hypertens 2013;31:1281-357. doi:10.1097/01.hjh.0000431740.32696.cc

50 Bejan-Angoulvant T, Saadatian-Elahi M, Wright JM, et al. Treatment of hypertension in patients 80 years and older: the lower the better? A meta-analysis of randomized controlled trials. J Hypertens 2010;28:1366-72. doi:10.1097/ HJH.Ob013e328339f9c5

51 Glynn RJ, Chae CU, Guralnik JM, Taylor JO, Hennekens CH. Pulse pressure and mortality in older people. Arch Intern Med 2000;160:2765-72. doi:10.1001/archinte.160.18.2765

52 Pastor-Barriuso R, Banegas JR, Damián J, Appel LJ, Guallar E. Systolic blood pressure, diastolic blood pressure, and pulse pressure: an evaluation of their joint effect on mortality. Ann Intern Med 2003;139:731-9. doi:10.7326/0003-4819-139-9-20031104000007

53 Avanzini F, Alli C, Boccanelli A, et al, GISSI-Prevenzione investigators High pulse pressure and low mean arterial pressure: two predictors of death after a myocardial infarction. / Hypertens 2006:24:237785. doi:10.1097/01.hjh.0000251897.40002.bf

Web appendix: Online supplemental material 